\title{
Coloring Exercises for Insect Identification and Conservation Awareness
}

\author{
Elizabeth Dawnette Knowlton ${ }^{1,}$, , Theresa Elizabeth Andrew ${ }^{1}$, Andrine Adeline Shufran ${ }^{2}$, \\ Kerri Maureen Farnsworth-Hoback ${ }^{1}$, William Wyatt Hoback ${ }^{2}$ \\ ${ }^{1}$ Environmental Science Graduate Program, Oklahoma State University, Stillwater, USA \\ ${ }^{2}$ Department of Entomology and Plant Pathology, Oklahoma State University, Stillwater, USA
}

Email address:

elise.knowlton@okstate.edu (E. D. Knowlton)

${ }^{*}$ Corresponding author

\section{To cite this article:}

Elizabeth Dawnette Knowlton, Theresa Elizabeth Andrew, Andrine Adeline Shufran, Kerri Maureen Farnsworth-Hoback, William Wyatt Hoback. Coloring Exercises for Insect Identification and Conservation Awareness. International Journal of Elementary Education. Vol. 8, No. 2, 2019, pp. 53-57. doi: 10.11648/j.ijeedu.20190802.13

Received: May 30, 2019; Accepted: July 4, 2019; Published: July 15, 2019

\begin{abstract}
The Endangered Species Act in the United States of America currently protects more than 1,500 species, 74 of which are insects, including the american burying beetle (ABB) and the rusty patched bumble bee. Insects that are experiencing population declines, such as the monarch butterfly, are under consideration for protection. Awareness of biological diversity, the ability to recognize an endangered species, and understanding the conservation of beneficial insects can begin at an early age. We designed a coloring exercise to promote insect species awareness and introduced this activity to elementary and middle school students in Tulsa, Oklahoma, USA. We assessed students' insect identification abilities by presenting a quiz on species diversity and $\mathrm{ABB}$ identification before and after the coloring exercise. Inspired by the quiz results, we created coloring templates for additional insect species, including the monarch butterfly, ladybird beetles, and bumble bees. These exercises will promote awareness of endangered species and improve science literacy in the classroom.
\end{abstract}

Keywords: Beneficial Insects, Population Declines, Coloring Templates for Identification

\section{Introduction}

Populations of many native insect species are declining in the United States of America (USA) and elsewhere in the world. A few species with documented declines include the american burying beetle (ABB), Nicrophorus amerianus (Olivier), bumble bees, Bombus spp., ladybird beetles, Coccinella novemnotata (Herbst) and Adalia bipunctata (Linnaeus), and the monarch butterfly, Danaus plexippus (Linnaeus). Members of the general public are promoting insect conservation by participating in citizen science: a form of collaboration among community members and scientists [1-4]. Positive outcomes from citizen science collaborations include community education and improved ecological literacy $[1,5,6]$.

Citizen science projects rely on public participation. However, insect literacy is often lacking [7]. Despite this, a growing number of citizen science projects focus on insects
$[8,9]$. Insect citizen science is accessible and usually lowcost. Some projects have led to the rediscovery and documentation of rare species.

For example, the Lost Ladybug Project invites citizen scientists from across North America to monitor ladybird beetle populations. Ladybird beetles are a diverse group with both native and introduced species, and the community of species has been changing $[10,11]$. Through citizen science efforts, the rare ninespotted lady beetle, $C$. novemnotata, has been rediscovered at various locations on the east coast [12]. Other citizen science projects, including Monarch Watch (http://www.monarchwatch.org/) have contributed important monitoring data leading to a better understanding of rare or declining species. Citizen scientists have tagged or tracked migrating monarch butterflies, helping to monitor populations and document migration paths [4, 13, 14].

American burying beetles were listed as federally endangered in 1989 (Federal Register 54[133]: 29652-55). Historical range of the ABB covered much of North America 
east of the Rocky Mountains; today, however, the ABB is found in isolated populations in only a few states [15].

Burying beetles benefit ecological communities. By burying small vertebrate carcasses for reproduction ([16] Scott 1998), they return nutrients to the soil available to plants. Unusual among insects, adult males and females exhibit extensive care of young; both parents feed the rapidly developing larvae and share in defense of the carcass against competitors [16, 17]. Burying beetles are rather conspicuous insects that are large (1-2" in length) with orange markings on black bodies, and often multiple species co-exist in a region. Due to coloration similarities within the genus, training is needed to identify ABB from related species.

We developed a burying beetle coloring exercise targeting K-12 classrooms and the general public. Participants were encouraged to color a blank beetle template (Figure 1), matching the pattern and markings to a given set of burying beetle species. Assessment of student learning after the coloring exercise indicated that students learned to identify the endangered $\mathrm{ABB}$ and differentiate other species of burying beetle. We offer additional coloring exercises for more insect groups and suggest teachers use this form of exercise to increase knowledge of biological diversity and insect identification.

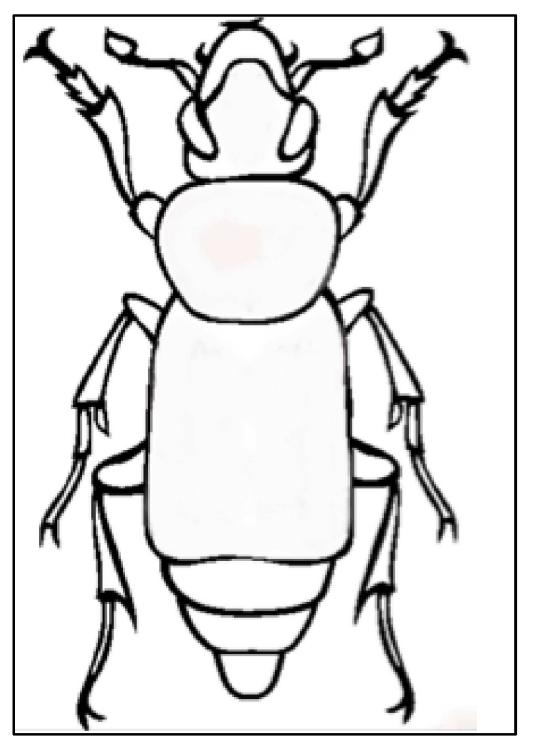

Figure 1. Body outline of a burying beetle, given to students to color during coloring exercise.

\section{ABB Coloring Exercise}

\subsection{Methods}

Following teacher-initiated volunteer participation in 2015, we presented our coloring exercise to four Tulsa, Oklahoma classrooms through the Global Gardens program (https://global-gardens.org/) and Rosa Parks Elementary School. A total of 71 students participated: 40 elementary school students and 31 middle school students.

Students received one uncolored beetle (Figure 1) in conjunction with a laminated picture of one of four burying beetle species: Nicrophorus americanus, Nicrophorus marginatus, Nicrophorus orbicollis, and Nicrophorus tomentosus. Students were asked to color the beetle like the given beetle in the laminated picture, replicating colors and markings of the beetle. When finished with coloring, we asked students if the beetle he or she colored was different from the beetles of nearby peers. We emphasized that different markings indicate a different species and challenged students to identify the beetle he or she colored.

\subsection{ABB Quiz and Quiz Results}

We directed a subset of third-grade students $(N=21)$ to take a quiz before and after the coloring exercise to assess identification learning. After a general introduction to the $\mathrm{ABB}$, we administered the "Before" quiz. The quiz consisted of four questions (Figure 2). The first question asked students to circle the endangered burying beetle among six burying beetles pictured (Figures 2-3). The second question asked students to name the endangered burying beetle. The third question referenced the picture of burying beetles (Figure 3) and asked students if the six burying beetles pictured were different and, if so, how? The fourth question was a multiple choice question asking students how many different species of beetle were pictured; answer choices were: (A) one (they are all the same species), (B) two, (C) four, and (D) six. After the coloring exercise, we administered the quiz again. We did not offer any alternative methods to coloring in our lesson plan.

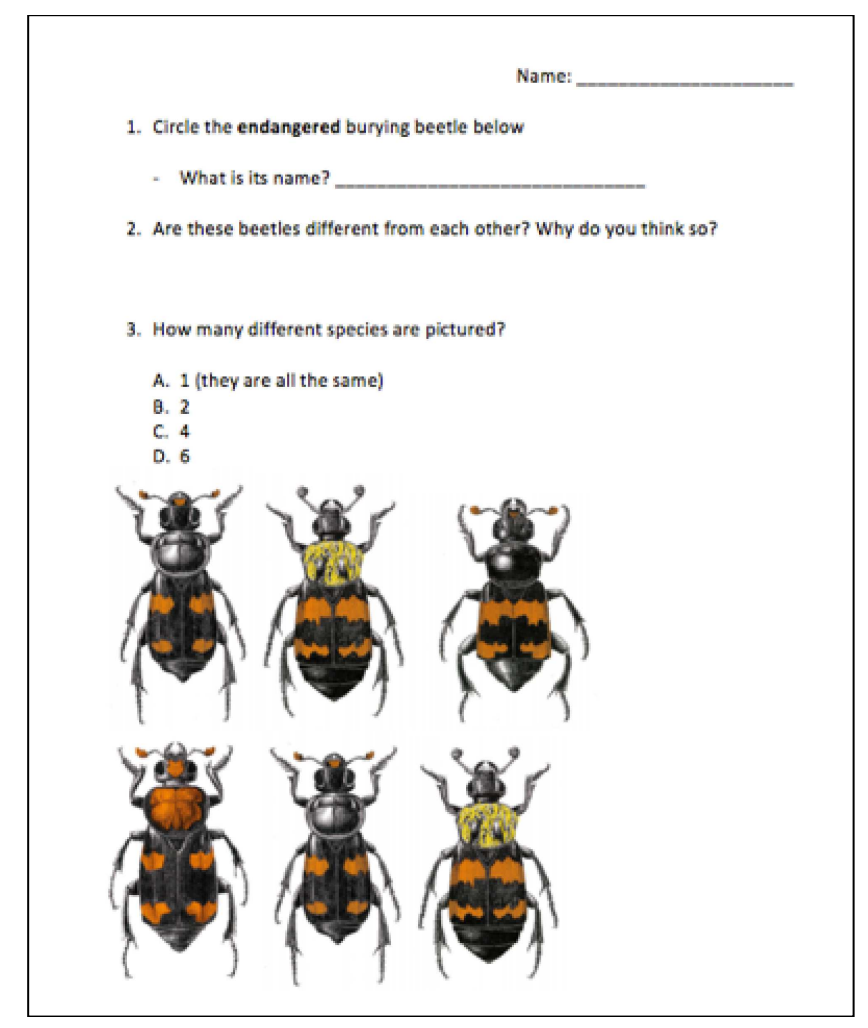

Figure 2. Quiz administered to students before and after coloring exercise. 


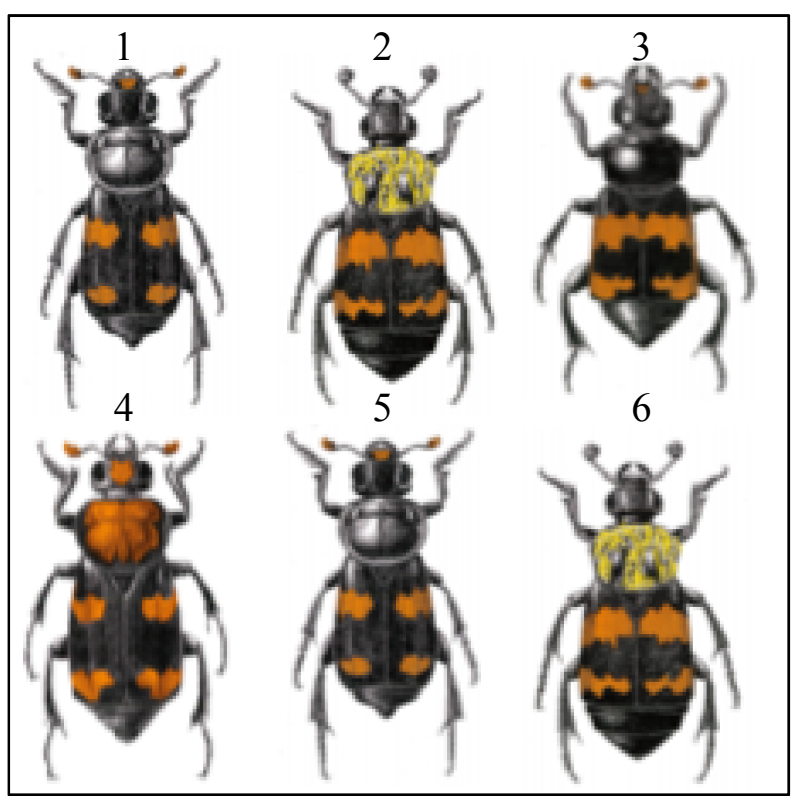

Figure 3. An assemblage of six burying beetles, the picture of which was given to students on the quiz. Nicrophorus orbicollis $=1 \& 5$, Nicrophorus tomentosus $=2 \& 6$, Nicrophorus marginatus $=3$, and Nicrophorus americanus $(A B B)=4$.

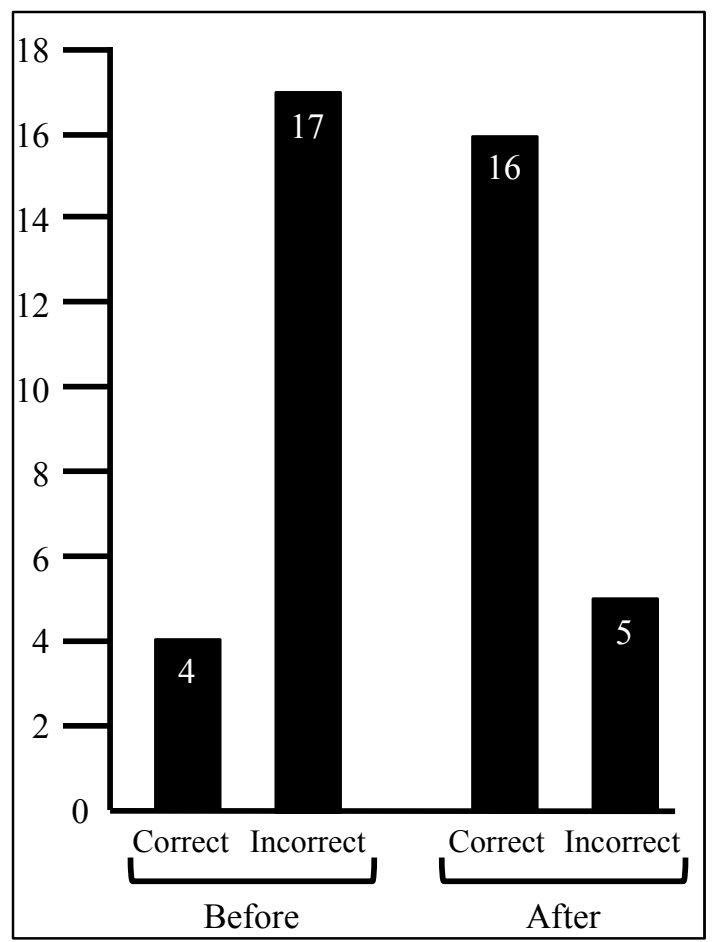

Figure 4. Correct and incorrect quiz responses to first question asking students to name the endangered burying beetle before and after beetle coloring exercise.

There was strong evidence of classroom learning. Before the coloring exercise, when students were asked to circle the correct picture of an $\mathrm{ABB}$, four students (19\%) answered correctly; however, after the coloring exercise, 16 students (76\%) answered correctly (Figure 4). In response to our second question asking students to name the endangered burying beetle, two students (10\%) answered "american burying beetle" before the coloring exercise and 17 students $(81 \%)$ answered american burying beetle after the coloring exercise. Students correctly answered the third question regardless of the coloring exercise. When asked if the burying beetles pictured were different and, if so, how, 17 students (before-quiz) and 18 students (after-quiz) answered, "Yes, because of different colors and patterns." Our last quiz question tended to be answered incorrectly regardless of the coloring exercise. In response to, "How many different species are pictured?" only seven students (before-quiz) and ten students (after-quiz) answered correctly.

\section{Conclusion}

\subsection{ABB Exercise}

The coloring exercise allowed students to learn how to identify the ABB based on pictorial or illustrative detail. When quizzed about $\mathrm{ABB}$ identification (quiz question 1), most students correctly identified an ABB after the coloring exercise (Figure 4). However, our educational materials were not sufficient in teaching the identifying features of burying beetle species other than the ABB. Students tended not to identify the number of species present in Figure 3 even though they understood that the different colors and patterns of burying beetles could be used to identify different species. A follow up with flash cards of individual beetles could help emphasize that different patterns and coloration reflect different species.

\subsection{Discussions}

Based on quiz results and positive teacher feedback, we developed additional coloring exercises to highlight identification of other endangered or declining insect species in the USA. We also present targeted comparisons of declining species versus prevalent species to broaden insect identification beyond these species. In the first new exercise, we expand upon the $\mathrm{ABB}$ material presented here to include a direct comparison of the endangered ABB to a commonly encountered species, the bordered burying beetle, N. marginatus. Students may choose to complete the blank template (right, Figure 5) by adding orange to the white patches and adding black patches to match each species.

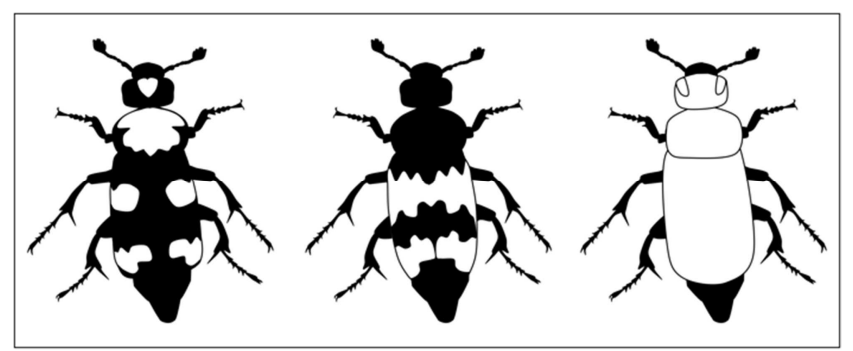

Figure 5. Burying beetle coloring exercise highlighting an endangered species, N. americanus (left), versus a prevalent species, Nicrophorus marginatus (middle); the white patches of both individuals can be seen as orange. The beetle on the right is a blank template for coloring. 
In the second new, untested exercise (Figure 6), we highlight the monarch butterfly, which is generally larger than the similar viceroy, Limenitis archippus (Cramer). The most visible, apparent difference between the species is that the viceroy has a horizontal line crossing all vertical veins on each hindwing that distinguishes it from the monarch. Monarchs are renowned for their extraordinary migration patterns, while the viceroy does not migrate. The viceroy's similar coloring is a classic example of Müllerian mimicry, where two species that are distasteful or toxic resemble each other.

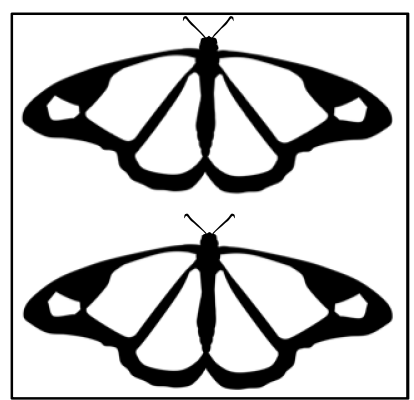

Figure 6. Butterfly coloring exercise with the monarch (upper panel, Danaus plexippus) and viceroy (lower panel, Limenitis archippus). The viceroy's hindwings are defined by the key distinguishing characteristic of transverse black lines (lower panel).

We also provide templates for the rare ninespotted lady beetle, Coccinella novemnotata, and the widespread exotic species, multicolored Asian lady beetle, Harmonia axyridis (Pallas) (Figures 7-8). Again, students may choose to add black spots to match the markings of each species. As well, students may choose to add only two black spots (one on each elytron or wing-cover) to Figure 7's template to match the species-specific markings of the twospotted lady beetle, Adalia bipunctata, also a declining native of the USA. In general, ladybird beetles are beneficial predators of aphid pests. These figures can be further used to illustrate other local ladybird beetle species so that students can learn to recognize several species and that some species are common while others are in decline. Depending on lesson plans, the teacher can lead students to examine biological control (e.g., ladybird beetles eating aphids) and the impacts of introduced species (such as the multicolored Asian lady beetle) on native species.

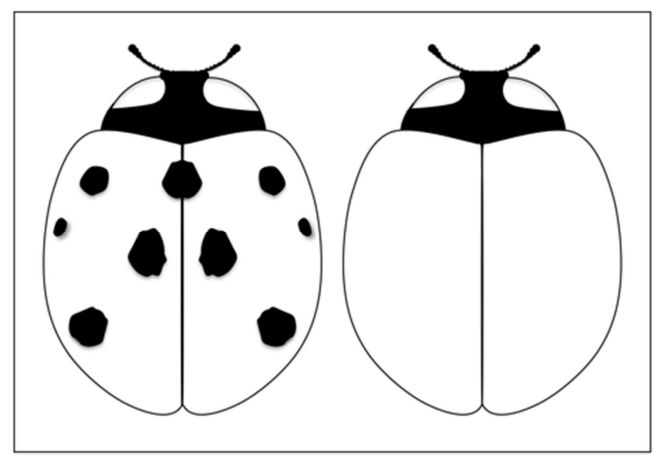

Figure 7. Coloring template for the rare ninespotted lady beetle (Coccinella novemnotata).

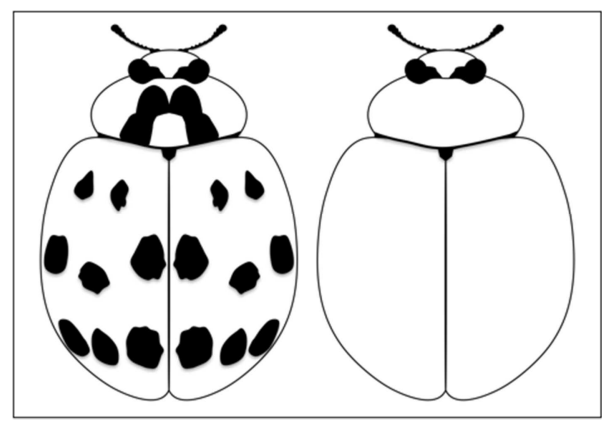

Figure 8. Coloring template for the prevalent multicolored Asian lady beetle (Harmonia axyridis).

Similar to the monarch and viceroy butterflies, many insects exhibit mimicry. While both of these butterflies are toxic (and therefore would be deterrent to any potential predator), other insects may only look harmful. For example, many flies will resemble bees and wasps because bees and wasps can sting while flies cannot. We provide a template for distinguishing between bumble bees and flies that look like bees (Figure 9). The most apparent differences are the antennae of the bee and the fly, and the connection between body regions, as well as wing number. The bee has a narrow waist while the fly has a color pattern to look like a bee. Bees are generally more hairy and actually have two pairs of wings, not just one pair like flies.

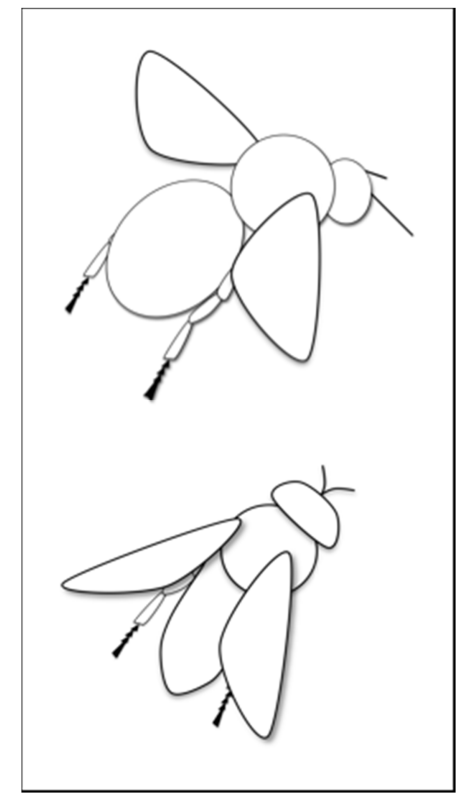

Figure 9. Coloring templates for a bumble bee (upper panel, Bombus sp.) compared to a fly (lower panel).

\section{References}

[1] Eitzel, M., Cappadonna, J., Santos-Lang, C., Duerr, R., Virapongse, A., West, S., Kyba, C., Bowser, A., Cooper, C., Sforzi, A., Metcalfe, A., Harris, E., Thiel, M., Haklay, M., Ponciano, L., Roche, J., Ceccaroni, L., Shilling, F., Dörler, D., Heigl, F., Kiessling, T., Davis, B. \& Jiang, Q. (2017) Citizen science terminology matters: Exploring key terms, Citizen Science: Theory and Practice, 2 (1) 1-20. 
[2] Pocock, M. J. O., Tweddle, J. C., Savage, J., Robinson, L. D. \& Roy, H. E. (2017) The diversity and evolution of ecological and environmental citizen science, PLoS ONE 12 (4): e0172579.

[3] Ellwood, E. R., Crimmins, T. M., \& Miller-Rushing, A. J. (2017) Citizen science and conservation: Recommendations for a rapidly moving field, Biological Conservation, 208, 1-4.

[4] James, D. G., James, T. S., Seymour, L., Kappen, L., Russell, T., Harryman, B., \& Bly, C. (2018) Citizen scientist tagging reveals destinations of migrating monarch butterflies, Danaus plexippus (L.) from the Pacific Northwest, Journal of the Lepidopterists' Society, 72, 127-144.

[5] Oberhauser, K. \& Prysby, M. (2008) Citizen science: Creating a research army for conservation, American Entomologist, 54 (2) 103-105.

[6] Rosenberger, D. W., \& Aukema, B. H. (2016) Stimulating curiosity and engagement with insects beyond the college classroom through citizen science, American Entomologist, 62: $120-122$.

[7] Pearson, G., Skinner, K. \& Hoback, W. (2007) Rearing the masses: Defining competencies for entomological literacy, American Entomologist, 53 (4) 216-223.

[8] Pocock, M. J. O., Roy, H. E., Fox, R., Ellis, W. N., \& Botham, M. (2017) Citizen science and invasive alien species: Predicting the detection of the oak processionary moth Thaumetopoea processionea by moth recorders, Biological Conservation, 208, 146-154.

[9] Ryan, S., Lombaert, E., Espeset, A., Vila, R., Talavera, G., Dincā, V., Renshaw, M. A., Eng, M. E., Doellman, M. M., Hornett, E. A., Li, Y., Pfrender, M. E., \& Shoemaker, D. (2018) Global invasion history of the world's most abundant pest butterfly: a citizen science population genomics study, bioRxiv. 1-56.
[10] Losey, J., Allee, L. \& Smyth, R. (2012) The Lost Ladybug Project: Citizen spotting surpasses scientist's surveys, American Entomologist, 58 (1) 22-24.

[11] Sickler, J., Cherry, T., Allee, L., Smyth, R. \& Losey, J. (2014) Scientific value and educational goals: Balancing priorities and increasing adult engagement in a citizen science project, Applied Environmental Education and Communication, 13 (2) 109-119.

[12] Losey, J., Perlman, J. \& Hoebeke, E. (2007) Citizen scientist rediscovers rare nine-spotted lady beetle, Coccinella novemnotata, in eastern North America, Journal of Insect Conservation, 11, 415-417.

[13] Urquhart, F. (1960) The monarch butterfly. London: Oxford University Press.

[14] Prysby, M. \& Oberhauser, K. (2004) Temporal and geographical variation in monarch densities: Citizen scientists document monarch population patterns. In The Monarch Butterfly: Biology and Conservation, Oberhauser, K. \& Solensky, M. (Eds.) pp. 9-20. Ithaca: Cornell University Press.

[15] Jurzenski, J., Jorgensen, C., Bishop, A., Grosse, R., Riens, J. \& Hoback, W. (2014) Identifying priority conservation areas for the American burying beetle, Nicrophorus americanus (Coleoptera: Silphidae), a habitat generalist, Systematics and Biodiversity, 12 (2) 149-162.

[16] Scott, M. (1998) The ecology and behavior of burying beetles, Annual Review of Entomology, 43, 595-618.

[17] Scott, M. (1990) Brood guarding and the evolution of male parental care in burying beetles, Behavioral Ecology and Sociobiology, 26 (1) 31-39. 